\title{
Multidisciplinary treatment of advanced or recurrent solid pseudopapillary neoplasm of the pancreas: three case reports
}

\author{
Kiyonori Tanoue ${ }^{10}$, Yuko Mataki ${ }^{1}$, Hiroshi Kurahara ${ }^{*}$, Tetsuya Idichi ${ }^{1}$, Yota Kawasaki ${ }^{1}$, Yoichi Yamasaki $^{1}$, \\ Yoshiaki Kita ${ }^{1}$, Yuto Hozaka' ${ }^{1}$ Hideyuki Oi ${ }^{1}$, Akihiro Nakajo' ${ }^{1}$, Takaaki Arigami ${ }^{2}$, Kosei Maemura ${ }^{3}$ and \\ Takao Ohtsuka'
}

\begin{abstract}
Background: Solid pseudopapillary neoplasm (SPN) is a rare pancreatic tumor that predominantly affects young females. Prognosis is excellent; however, $10-15 \%$ of patients show metastasis at the time of surgery or develop tumor recurrence after pancreatectomy.

Case presentation: We reviewed the clinical course of three patients with advanced or recurrent SPN and subsequently underwent multidisciplinary treatment at our institution between 2002 and 2019. The primary tumor was resected in all three patients, and metastases were also resected if indicated. Intensive combined therapy, including re-resection, chemotherapy, ablation, arterial chemoembolization, and radiation therapy, allowed all patients to survive for a long time. The literature review showed that resection seems to be more effective than other treatments for metastatic SPN.
\end{abstract}

Conclusions: Multidisciplinary treatment, including resection, may improve the prognosis of patients with SPN with recurrence or metastasis.

Keywords: Solid pseudopapillary neoplasm, Frantz tumor, Malignancy, Multidisciplinary treatment

\section{Background}

Solid pseudopapillary neoplasm (SPN) of the pancreas, also known as Frantz's tumor, is rare and usually carries a favorable prognosis, with a 5 -year survival rate of up to $97 \%$ [1-3]. However, up to $10-15 \%$ of affected patients have distant metastasis [4]. Because of its rarity, many controversies remain regarding treatment for recurrent or metastatic SPN. Herein, we report three patients with recurrent and metastatic SPN who underwent multidisciplinary treatment and discuss the efficacy of the treatment using a literature review.

\footnotetext{
*Correspondence: h-krhr@m3.kufm.kagoshima-u.ac.jp

${ }^{1}$ Department of Digestive Surgery, Breast and Thyroid Surgery, Kagoshima University Graduate School of Medical and Dental Sciences, 8-35-1 Sakuragaoka, Kagoshima 890-8520, Japan

Full list of author information is available at the end of the article
}

\section{Case presentation}

Patient No. 1 was a 49-year-old female who underwent computed tomography (CT) scan for a pancreatic tumor detected by abdominal ultrasound during her annual check-up. The CT scan highlighted a pancreatic tumor in the pancreatic tail, which was $7 \mathrm{~cm}$ in diameter, and multiple liver metastases in subsegments 2, 4, and 7 (Fig. 1a). After chemotherapy using gemcitabine (GEM) plus S-1, which led to a slight increase in the size of the tumor while no other new lesion was formed, we performed distal pancreatectomy (DP) and resection of all the metastatic liver tumors. Pathological examination showed SPN with a $3 \%$ Ki-67 index and liver metastases of SPN. Ten months later, solitary hepatic recurrences were observed in subsegments 2 and 4 (Fig. 1b). The metastasis in subsegment 2 was resected, and that in subsegment 

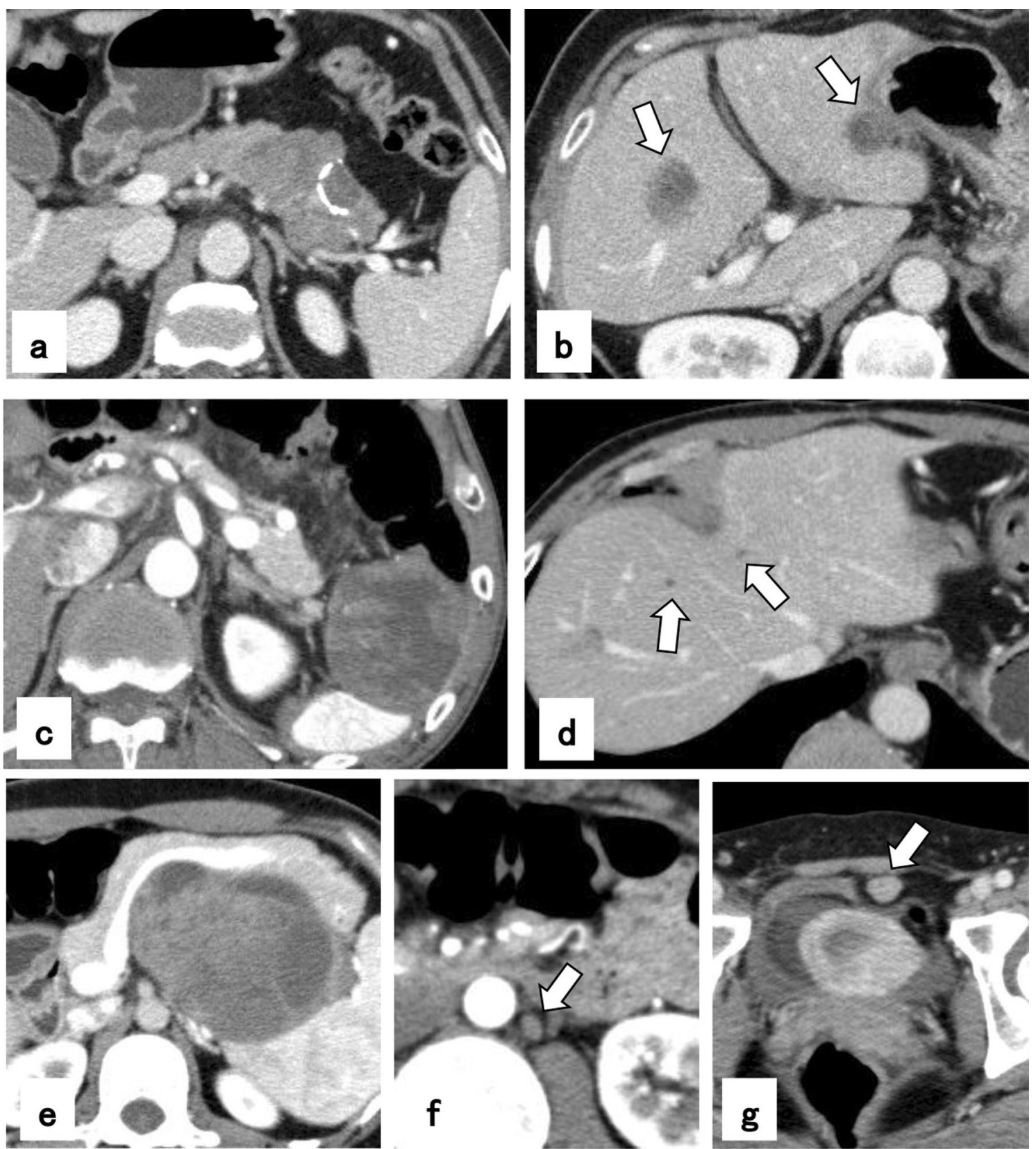

Fig. 1 a Computed tomography (CT) image of the primary tumor in a solid pseudopapillary neoplasm (SPN) (Patient No. 1). b CT image of liver metastases 10 months after resection of the primary tumor (Patient No. 1). c CT image of the main tumor in SPN (Patient No. 2). $\mathbf{d}$ CT image of multiple liver metastases 9 months after resection of the primary tumor (Patient No. 2). e CT image of the primary tumor in SPN (Patient No. 3). $\mathbf{f} C T$ image of synchronous para-aortic lymph node metastasis (Patient No. 3). $\mathbf{g}$ CT image of peritoneal wall metastasis in the anterior wall of the urinary bladder (Patient No. 3)

4 was treated by radiofrequency ablation (RFA). Sixteen months later, re-recurrence was noted in multiple sites of the liver, which was a contraindication for surgery, and she underwent transcatheter arterial chemoembolization (TACE) as well as transcatheter arterial infusion (TAI) of epirubicin hydrochloride 9 times in 34 months.
Thereafter, she underwent whole-liver irradiation, and she has survived for an additional 11 months to date (a total of 111 months after the initial diagnosis).

Patient No. 2 was a 57-year-old male who underwent a CT scan for gastric ulcer perforation, and a pancreatic tumor measuring $7 \mathrm{~cm}$ was incidentally detected 
(Fig. 1c). After emergency surgery for the perforated gastric ulcer, the patient underwent DP, and the pathological results revealed SPN with capsule invasion. Nine months later, the patient suffered from multiple liver metastases in the subsegments $4,6,7$, and 8 , with a total number of 9 metastases (Fig. 1d). After 2 months of chemotherapy using GEM plus S-1, which led to a slight increase in the size of the metastases, we performed multiple partial resections of the liver to achieve $\mathrm{R} 0$ resection. This patient had survived for 50 months without any sign of re-recurrence to date (a total of 79 months after the initial diagnosis).

Patient No. 3 was a 30-year-old female who underwent a CT scan for suspected tuberculosis. The CT scan revealed a pancreatic tumor, measuring $10 \mathrm{~cm}$ in diameter with para-aortic lymph node (\#16b1 latero) and abdominal wall metastases (Fig. 1e-g). We resected the pancreatic tumor, together with a sampling of the metastatic lymph nodes and the abdominal wall. Pathological results revealed SPN with $\mathrm{a}<1 \% \mathrm{Ki}-67$ index and capsule invasion. Then, we performed a histoculture drug response assay (HDRA), a chemosensitivity test reported by Hoffman [5]. The test showed high sensitivity to paclitaxel, and thus, the patient received chemotherapy using S-1 plus paclitaxel. Paclitaxel treatment for SPN is not covered by the Japanese National Health Insurance, so this patient provided informed consent and paid for the treatment. Thereafter, the lymph node metastases showed stability for 163 months. Because of the increasing accumulation in the para-aortic lymph node (\#16b1 latero) on fluorodeoxyglucose position emission tomography without any other lesion, we performed resection of the metastatic lymph nodes, and thereafter, she has survived for an additional 14 months without any sign of recurrence to date (total 183 months after initial diagnosis).

\section{Discussion}

Because metastasis or recurrence of SPN is rare, there has been little investigation into its treatment. Resection is also considered optimal for recurrent and metastatic lesions but has little supportive evidence. According to the data from 77 SPN patients who received treatment for distant metastasis, recurrence, and/or invasions of adjacent organs in previous reports [4, 6-35] (Table 1), patients who underwent resection $(n=57)$ had a significantly better prognosis than patients who underwent non-surgical treatment $(n=20)$ (median overall survival, 36 months vs. 31 months, $p=0.0244)$. Although selection bias may exist in the literature review, resection of metastatic or recurrent SPN, if applicable, may contribute to improving the patient's prognosis. Among the above-mentioned 77 patients, 33 were treated with resection only, while 44 patients were treated with nonsurgical treatment. In those 44 patients, the efficacy of non-surgical treatment for SPN was evaluated for each treatment modality (Table 1 ).

Soloni et al. reported that cisplatin, 5-fluorouracil (5-FU), and GEM were the most frequently used chemotherapeutic agents in treating unresectable SPN [10]. In their review, some benefit was observed following cisplatin administration in 5 of 8 patients, 5-FU in 3 of 8 patients, and GEM in 2 of 6 patients. However, SPN is a slow-growing tumor and usually shows stable condition even without chemotherapeutic agents; therefore, the efficacy of these drugs in SPN remains unclear. We used GEM plus S-1 in patients No. 1 and 2, according to the regimen for pancreatic ductal adenocarcinoma; however, the tumor had increased slightly in size after chemotherapy in both patients. It is anticipated that there will be many patients with SPN who will not respond to these chemotherapies. In fact, our data from the literature indicate that only a few patients have achieved tumor reduction with chemotherapy and that there is no clearly effective regimen for SPN. However, it is possible that cisplatin may be effective, as all regimens that showed tumor reduction included cisplatin (Table 1).

In this report, one patient showed sensitivity to paclitaxel in HDRA, and para-aortic lymph node metastasis kept the stable disease in the long-term after paclitaxel treatment. Only one previous study [21] reported chemosensitivity tests for recurrent and metastatic SPN. In that study, the collagen gel droplet embedded culture drug sensitivity test showed that GEM was the most sensitive agent, and they subsequently used it as adjuvant chemotherapy after resection of recurrent lesions. Their patient had no recurrence for 18 months after the second operation. In the future, such patient-specific chemosensitivity tests may be useful for the adequate selection of chemotherapeutic agents in treating malignant SPN.

The efficacy of other non-surgical treatments such as TACE, TAI, and RFA was not definitive in our patients, nor was it evident in data from the literature. However, there are 5 case reports in the literature about the reduction effect of radiation therapy on SPN [22, 32-35], and Kodama et al. [29] reported that in a patient who had liver and lymph node metastases 15 years after an initial operation, proton therapy reduced his tumor size despite the resistance to GEM plus nab-paclitaxel (Table 1). Liver transplantation was also reported to be useful for treating multiple liver metastases from SPN in four cases [16, $22,23,36]$. These treatments could be an option for unresectable SPN. 
Table 1 Characteristics of 77 SPN patients with malignant behavior (distant metastasis, recurrence and/or invasion) in the literature

\begin{tabular}{|c|c|c|}
\hline Patient characteristics & Number of patients & References \\
\hline Age, median years (range) & $24(7-66)^{*}$ & {$[4,6-35]$} \\
\hline Male/female/unknown & $8 / 54 / 15$ & {$[4,6-35]$} \\
\hline Location of main tumor, head/body or tail/unknown & $13 / 36 / 28$ & {$[4,6-35]$} \\
\hline \multicolumn{3}{|l|}{ Metastatic and recurrent site (\%) } \\
\hline Liver & $44(57.1)$ & {$[4,6-35]$} \\
\hline Lung & $3(3.9)$ & {$[4,6-35]$} \\
\hline Peritoneum & $19(24.7)$ & {$[4,6-35]$} \\
\hline Lymph node & $9(11.7)$ & {$[4,6-35]$} \\
\hline Local & $18(23.4)$ & {$[4,6-35]$} \\
\hline Others & $6(7.8)$ & {$[4,6-35]$} \\
\hline \multicolumn{3}{|c|}{$\begin{array}{l}\text { Non-surgical treatment effect, tumor reduction/no response/missing data } \\
\text { (total number) }\end{array}$} \\
\hline GEM-based regimen & $0 / 6 / 4(10)$ & {$[10,17,19,21,23,29]$} \\
\hline CDDP-based regimen & $2 / 2 / 2(6)$ & {$[10,17,18]$} \\
\hline 5-FU-based regimen & $0 / 3 / 2(5)$ & {$[8,10,20]$} \\
\hline $\mathrm{CDDP}+5-\mathrm{FU}$ & $2 / 0 / 3(5)$ & {$[10,25,26]$} \\
\hline Interferon & $0 / 1 / 2(3)$ & {$[10,32]$} \\
\hline Tamoxifen & $0 / 2 / 0(2)$ & {$[8,10]$} \\
\hline GEM + CDDP & $1 / 1 / 0(2)$ & {$[10,31]$} \\
\hline Somatostatin & $0 / 1 / 0(1)$ & [10] \\
\hline Capecitabine & $0 / 1 / 0(1)$ & [10] \\
\hline Paclitaxel & $0 / 1 / 0(1)$ & [19] \\
\hline Thalidomide & $0 / 1 / 0(1)$ & {$[10]$} \\
\hline Imatinib & $0 / 1 / 0(1)$ & [10] \\
\hline Oxaliplatin-based regimen & $0 / 1 / 0(1)$ & [10] \\
\hline Erlotinib & $0 / 1 / 0(1)$ & [23] \\
\hline RFA & $0 / 3 / 4(7)$ & {$[7,10,17]$} \\
\hline RT & $5 / 0 / 0(5)$ & {$[22,32-35]$} \\
\hline CRT & $0 / 1 / 1(2)$ & {$[10]$} \\
\hline TAl & $0 / 1 / 1(2)$ & {$[10,23]$} \\
\hline TACE & $1 / 0 / 1(2)$ & {$[8,23]$} \\
\hline HIPEC & $0 / 1 / 1(2)$ & {$[11,30]$} \\
\hline TAE & $0 / 1 / 0(1)$ & [10] \\
\hline $\mathrm{MCN}$ & $0 / 1 / 0(1)$ & [10] \\
\hline SIRT & $0 / 0 / 1(1)$ & [17] \\
\hline CS-PHP & $1 / 0 / 0(1)$ & [31] \\
\hline Proton beam therapy & $1 / 0 / 0(1)$ & [29] \\
\hline
\end{tabular}

GEM gemcitabine, CDDP cisplatin, 5-FU 5-fluorouracil, RFA radiofrequency ablation, $R T$ radiation therapy, CRT chemoradiotherapy, TAl transcatheter arterial infusion, TACE transcatheter arterial chemoembolization, HIPEC hyperthermic intraperitoneal chemotherapy, TAE transcatheter arterial embolization, $M C N$ microwave coagulonecrotic therapy, SIRT selective internal radiation therapy, CS-PHP chemosaturation with percutaneous hepatic perfusion

* Only 62 patients' data were available

\section{Conclusion}

Multidisciplinary treatment, including resection, may improve the prognosis of patients with SPN with recurrence or metastasis.

\section{Abbreviations}

5-FU: 5-Fluorouracil; CT: Computed tomography; DP: Distal pancreatectomy; GEM: Gemcitabine; HDRA: Histoculture drug response assay; RFA:
Radiofrequency ablation; SPN: Solid pseudopapillary neoplasm; TACE: Transcatheter arterial chemoembolization; TAl: Transcatheter arterial infusion.

\section{Acknowledgements}

This work was supported by JSPS KAKENHI Grant Number JP2OH03753 and JP20K21633.

\section{Authors' contributions}

$K T, Y M$, and HK drafted the manuscript. TI, YK, YY, YH, HO, TA, and KM managed and treated the patients and collected the data. YK and AN helped in drafting the manuscript. TO supervised the writing of the manuscript. All 
authors discussed the content of the manuscript, read and approved the final manuscript.

\section{Funding}

Japan Society for the Promotion of Science, JP2OH03753, Takao Ohtsuka, JP20K21633, Takao Ohtsuka.

\section{Availability of data and materials}

The datasets supporting the conclusions of this article are included within the article and its additional files.

\section{Declarations}

\section{Ethics approval and consent to participate}

Not applicable.

\section{Consent for publication}

Written informed consent was obtained from the patients for publication of these case reports and any accompanying images.

\section{Competing interests}

The authors declare that they have no competing interests.

\section{Author details}

${ }^{1}$ Department of Digestive Surgery, Breast and Thyroid Surgery, Kagoshima University Graduate School of Medical and Dental Sciences, 8-35-1 Sakuragaoka, Kagoshima 890-8520, Japan. ²Department of Onco-Biological Surgery, Kagoshima University Graduate School of Medical and Dental Sciences, Kagoshima, Japan. ${ }^{3}$ Department of Digestive Surgery, Kagoshima City Hospital, Kagoshima, Japan.

Received: 14 November 2021 Accepted: 3 January 2022

Published online: 10 January 2022

\section{References}

1. Luttges J. What's new? The 2010 WHO classification for tumours of the pancreas. Pathologe. 2011;32(Suppl 2):332-6.

2. Papavramidis T, Papavramidis S. Solid pseudopapillary tumors of the pancreas: review of 718 patients reported in English literature. J Am Coll Surg. 2005:200(6):965-72.

3. Klimstra DS, Wenig BM, Heffess CS. Solid-pseudopapillary tumor of the pancreas: a typically cystic carcinoma of low malignant potential. Semin Diagn Pathol. 2000;17(1):66-80.

4. Kang CM, Kim KS, Choi JS, Kim H, Lee WJ, Kim BR. Solid pseudopapillary tumor of the pancreas suggesting malignant potential. Pancreas. 2006;32(3):276-80.

5. Hoffman RM. Three-dimensional histoculture: origins and applications in cancer research. Cancer Cells. 1991;3(3):86-92.

6. Gomez P, Yorke R, Ayala AG, Ro JY. Solid-pseudopapillary neoplasm of pancreas with long delayed liver metastasis. Ann Diagn Pathol. 2012;16(5):380-4

7. Hanada K, Kurihara K, Itoi T, Katanuma A, Sasaki T, Hara K, et al. Clinical and pathological features of solid pseudopapillary neoplasms of the pancreas: a nationwide multicenter study in Japan. Pancreas. 2018;47(8):1019-26.

8. Horisawa M, Niinomi N, Sato T, Yokoi S, Oda K, Ichikawa M, et al. Frantz's tumor (solid and cystic tumor of the pancreas) with liver metastasis: successful treatment and long-term follow-up. J Pediatr Surg. 1995:30(5):724-6.

9. Ky A, Shilyansky J, Gerstle J, Taylor G, Filler RM, Grace N, et al. Experience with papillary and solid epithelial neoplasms of the pancreas in children. J Pediatr Surg. 1998;33(1):42-4.

10. Soloni P, Cecchetto G, Dall'igna P, Carli M, Toffolutti T, Bisogno G. Management of unresectable solid papillary cystic tumor of the pancreas. A case report and literature review. J Pediatr Surg. 2010:45(5):e1-6.

11. Wu J, Tian X, Liu B, Li C, Hao C. Features and treatment of peritoneal metastases from solid pseudopapillary neoplasms of the pancreas. Med Sci Monit. 2018:24:1449-56.
12. Martin RC, Klimstra DS, Brennan MF, Conlon KC. Solid-pseudopapillary tumor of the pancreas: a surgical enigma? Ann Surg Oncol. 2002:9(1):35-40.

13. Nishihara K, Nagoshi M, Tsuneyoshi M, Yamaguchi K, Hayashi I. Papillary cystic tumors of the pancreas. Assessment of their malignant potential. Cancer. 1993;71(1):82-92.

14. Chen X, Zhou GW, Zhou HJ, Peng CH, Li HW. Diagnosis and treatment of solid-pseudopapillary tumors of the pancreas. Hepatobiliary Pancreat Dis Int. 2005:4(3):456-9.

15. Sanfey H, Mendelsohn G, Cameron JL. Solid and papillary neoplasm of the pancreas. A potentially curable surgical lesion. Ann Surg. 1983;197(3):272-5.

16. Kocman B, Jadrijevic S, Skopljanac A, Mikulic D, Gustin D, Buhin M, et al. Living donor liver transplantation for unresectable liver metastases from solid pseudo-papillary tumor of the pancreas: a case report. Transplant Proc. 2008;40(10):3787-90.

17. Krug S, Bartsch DK, Schober M, Librizzi D, Pfestroff A, Burbelko M, et al. Successful selective internal radiotherapy (SIRT) in a patient with a malignant solid pseudopapillary pancreatic neoplasm (SPN). Pancreatology. 2012;12(5):423-7.

18. Lee SE, Kwon Y, Jang JY, Kim YH, Hwang DW, Kim MA, et al. The morphological classification of a serous cystic tumor (SCT) of the pancreas and evaluation of the preoperative diagnostic accuracy of computed tomography. Ann Surg Oncol. 2008;15(8):2089-95.

19. Morikawa T, Onogawa T, Maeda S, Takadate T, Shirasaki K, Yoshida $\mathrm{H}$, et al. Solid pseudopapillary neoplasms of the pancreas: an 18-year experience at a single Japanese Institution. Surg Today. 2013;43(1):26-32.

20. Santos D, Calhau A, Bacelar F, Vieira J. Solid pseudopapillary neoplasm of pancreas with distant metastasis during pregnancy: a diagnostic and treatment challenge. BMJ Case Rep. 2020. https://doi.org/10.1136/ bcr-2020-237309.

21. Shimizu T, Murata S, Mekata E, Miyake T, Abe H, Kurumi Y, et al. Clinical potential of an antitumor drug sensitivity test and diffusion-weighted MRI in a patient with a recurrent solid pseudopapillary tumor of the pancreas. J Gastroenterol. 2007;42(11):918-22.

22. Wojciak M, Gozdowska J, Pacholczyk M, Lisik W, Kosieradzki M, Cichocki A, et al. Liver transplantation for a metastatic pancreatic solidpseudopapillary tumor (Frantz Tumor): a case report. Ann Transplant. 2018:23:520-3.

23. Dovigo AG, Diaz MB, Gutierrez MG, Selles CF, Grobas JP, Valladares $M$, et al. Liver transplantation as treatment in a massive metastasis from Gruber-Frantz pancreatic tumor: a case report. Transplant Proc. 2011;43(6):2272-3.

24. Shaikh S, Arya S, Ramadwar M, Barreto SG, Shukla PJ, Shrikhande SV. Three cases of unusual solid pseudopapillary tumors. Can radiology and histology aid decision-making? JOP. 2008;9(2):150-9.

25. Guo N, Zhou QB, Chen RF, Zou SQ, Li ZH, Lin Q, et al. Diagnosis and surgical treatment of solid pseudopapillary neoplasm of the pancreas: analysis of 24 cases. Can J Surg. 2011;54(6):368-74.

26. Tipton SG, Smyrk TC, Sarr MG, Thompson GB. Malignant potential of solid pseudopapillary neoplasm of the pancreas. Br J Surg. 2006;93(6):733-7.

27. Vassos N, Agaimy A, Klein P, Hohenberger W, Croner RS. Solid-pseudopapillary neoplasm (SPN) of the pancreas: case series and literature review on an enigmatic entity. Int J Clin Exp Pathol. 2013;6(6):1051-9.

28. Huffman BM, Westin G, Alsidawi S, Alberts SR, Nagorney DM, Halfdanarson TR, et al. Survival and prognostic factors in patients with solid pseudopapillary neoplasms of the pancreas. Pancreas. 2018:47(8):1003-7.

29. Kodama R, Koh Y, Midorikawa H, Yokota Y, Saegusa H, Ushimaru H. A case of recurrence of a solid pseudopapillary neoplasm of the pancreas effectively treated with proton beam radiotherapy. Clin J Gastroenterol. 2021;14(1):375-81.

30. Wu H, Huang YF, Liu XH, Xu MH. Extrapancreatic solid pseudopapillary neoplasm followed by multiple metastases: case report. World J Gastrointest Oncol. 2017;9(12):497-501.

31. Hofmann $H$, von Haken $R$, Werner J, Kortes $N$, Bergmann F, Schemmer $P$ et al. Unresectable isolated hepatic metastases from solid pseudopapillary neoplasm of the pancreas: a case report of chemosaturation with high-dose melphalan. Pancreatology. 2014;14(6):546-9.

32. Cappellari JO, Geisinger KR, Albertson DA, Wolfman NT, Kute TE. Malignant papillary cystic tumor of the pancreas. Cancer. 1990;66(1):193-8. 
33. Fried P, Cooper J, Balthazar E, Fazzini E, Newall J. A role for radiotherapy in the treatment of solid and papillary neoplasms of the pancreas. Cancer. 1985;56(12):2783-5.

34. Zinner MJ, Shurbaji MS, Cameron JL. Solid and papillary epithelial neoplasms of the pancreas. Surgery. 1990;108(3):475-80.

35. Zauls JA, Dragun AE, Sharma AK. Intensity-modulated radiation therapy for unresectable solid pseudopapillary tumor of the pancreas. Am J Clin Oncol. 2006;29(6):639-40.

36. Sumida W, Kaneko K, Tainaka T, Ono Y, Kiuchi T, Ando H. Liver transplantation for multiple liver metastases from solid pseudopapillary tumor of the pancreas. J Pediatr Surg. 2007;42(12):e27-31.

\section{Publisher's Note}

Springer Nature remains neutral with regard to jurisdictional claims in published maps and institutional affiliations.

\section{Submit your manuscript to a SpringerOpen ${ }^{\circ}$ journal and benefit from:}

- Convenient online submission

- Rigorous peer review

- Open access: articles freely available online

- High visibility within the field

- Retaining the copyright to your article

Submit your next manuscript at $\boldsymbol{\nabla}$ springeropen.com 